\title{
Developing a Reflective Self in Cyber Space
}

\author{
Ringel, Shoshana; Mishna, Faye; Sanders, Jane
}

Version Pre-Print/ Submitted Manuscript

Citation Ringel, S., Mishna, F., \& Sanders, J. (2016). Developing a Reflective Self

(published version) in Cyber Space. Psychoanalytic Psychology. Advance online publication. doi: $10.1037 /$ pap0000113

Publisher's Statement This article may not exactly replicate the authoritative document published in the APA journal. It is not the copy of record.

How to cite TSpace items

Always cite the published version, so the author(s) will receive recognition through services that track citation counts, e.g. Scopus. If you need to cite the page number of the TSpace version (original manuscript or accepted manuscript) because you cannot access the published version, then cite the TSpace version in addition to the published version using the permanent URI (handle) found on the record page. 


\title{
Developing a Reflective Self through Cyber Space
}

\author{
Abstract \\ This paper will address how cyber technology may facilitate reflective functioning with \\ patients who present with primitive self states, fragmentation and dissociation. The utilization of \\ text-based information and communication technology may allow for a reflective space, apart \\ from the therapist's explicit intrusion and the potential danger of abandonment and rejection, and \\ may help develop the capacity for reflection and symbolization. Through a case illustration and \\ research findings, we will discuss the benefits and challenges of using cyber technology as an \\ adjunct to face to face treatment.*
}

Key words: Cyber technology, reflective functioning, dissociation, attachment, BPD 
The purpose of this paper is to discuss how text-based forms of communication using cyber technology may facilitate reflective functioning with patients who present with primitive self states, fragmentation and dissociation. The utilization of text-based information and communication technology (ICT) may allow for a reflective space, apart from the therapist's explicit intrusion and the potential danger of abandonment and rejection, and may help develop the capacity for reflection and symbolization. For patients who may be hyper-vigilant during a face-to-face therapeutic encounter, cyber communication can allow for the development of the capacity for reflection and symbolization that can otherwise be overwhelmed by affective instability and ongoing crises during direct proximal interactions. A case illustration will highlight the use of e-mail to foster more open expression, allowing space for deeper reflection that can be further strengthened when brought into the face to face therapeutic process.

Janet (1925) was one of the first clinicians to distinguish between normal narrative memory in which familiar experiences are stored and integrated into narrative sequence, and traumatic memory, in which frightening or novel experience sustains "particular vividness" (van der Kolk, 2002) and may remain fragmented and dissociated. While in some cases, these memories are dissociated, discrete aspects may later manifest through enactments, intense affective response, nightmares, images, or sensorimotor experience (van der Kolk, 2002). Bromberg (2011) suggests that during dissociative episodes, fragmented self states in the patient may trigger dissociation in the analyst, and that the analytic dyad then engages in mutually dissociated enactments that might be recognized and processed only at a later point in the treatment.

*A shorter version of this paper was presented at the 2015, IARPP $12^{\text {th }}$ Annual Conference, Toronto, Canada 
Fragmentation and dissociation may develop in the context of attachment insecurity and disorganization when fear is a dominant affect in the attachment system following inconsistent and unreliable responsiveness by primary caregivers on whom the child is dependent for care and survival (Slade, 2014). The child may then develop affective and behavioral strategies, such as aggressive behaviors or anxiety, to manage rejection, shaming, and lack of attunement by the caregiver (Lyons-Ruth, Dutra, Schuder \& Bianchi, 2006). Such child/parent interactions foreshadow the patient/therapist relationship, which may mirror earlier relational trauma associated with perceived rejection and fear of abandonment. A pattern of ongoing crisis and disruption in the therapeutic bond may interfere with the potential space that typically develops in the context of attachment safety and security, and allows for the development of insight and mentalization functions (Fonagy \& Bateman, 2008). With these patients, face-to-face interactions may at times be too destabilizing to allow both the patient and the therapist to utilize their reflective capacities.

\section{Information and Communication Technology (ICT) in Therapy}

The rapid increase of information and communication technology has revolutionized how individuals of all ages interact (Migone, 2013; Perron, Taylor, Glass, \& Margerum-Leys, 2010). Along with the tremendous accessibility and ease of online messaging, there has been a transformational emergence and popularity of social networking sites, such as Twitter, Facebook, Tumblr, and Instagram, among many others. The number of users worldwide has increased exponentially, as have the ever expanding local and global networks and opportunities for learning, entertainment, and support (Blais, Craig, Pepler, \& Connolly, 2008; Mishna, Bogo, Root, \& Fantus, 2014). 
With the exponential increase of handheld devices, individuals of all ages now utilize text-based communication with fluency and ease. Moreover, ICTs have led to transformative changes across professional fields (Bradley, Hendricks, Lock, Whiting, \& Parr, 2011; Tunick Mednick, \& Conroy, 2011). There is a growing body of literature on formal ICT programs and interventions, such as e-counseling and tele-psychology (Dowling \& Rickwood, 2013; Hanley, 2009; Richards \& Vigano, 2013). In formal ICT interventions, ICT is typically the standalone mode of service provision. In this model of service delivery, online/e-therapy consists of interventions or support offered through synchronous (e.g., chat) or asynchronous (e.g., email) communication, with encryption and firewall protections to ensure confidentiality (Abbott, Klein, \& Ciechomski, 2008; Murphy, Parnass, Mitchell, Hallett, Cayley, \& Seagram, 2009). Online therapeutic interventions have been found to be effective (Barak, Hen, Boniel-Nissim, \& Shapira, 2008; Dunn, 2012) and the therapeutic relationship / alliance in e-therapy has been found to be equivalent overall to that in traditional face-to-face therapy (Hanley 2009; Preschl, Maercker, \& Wagner, 2011).

In addition to formal online programs, ICTs have become integrated into therapeutic interventions through formal blending of online modules with face-to-face therapy (van der Vaart, Witting, Riper, Kooistra, Bohlmeijer, \& van Gemert-Pijnen, 2014). This model of intervention combines online interventions and strategies with face-to-face sessions, whereby part of the intervention entails some online programs or exercises in addition to or replacing a number of face-to-face sessions. Both the online and the face-to-face components are formal, structured and monitored. Online exercises may include homework assignments, psychoeducational activities, or assessment tools. 
In contrast to this structured use of ICT in therapy, the current paper will consider the use of less structured, “informal” (Mishna, Fantus_\& McInroy, 2016) or “adjunctive” (Peterson \& Beck, 2003) use of text-based communication technology, within the therapeutic environment. As cyber technology has increasingly begun to filter into the clinical environment it is fast becoming an informal part of traditional face-to-face therapy as well, for administrative purposes and as a therapeutic exchange between therapists and clients (Gabbard, Kassaw, \& Perez-Garcia, 2011; Mishna, Bogo, Root, Sawyer, \& Khoury-kassabri, 2012; Mishna, Bogo, \& Sawyer, 2015). Specifically, information and communication technology has begun to become incorporated into traditional therapeutic practice as an informal concurrent mode of communication, an adjunct to the face-to-face sessions or contact. The reference to this use of technology as "informal" is not to suggest it is, or should be, untethered to the analytic processes of therapy. Rather, as an adjunct to face-to-face therapy, any use of ICT should be incorporated into the context of the analytic process and given as careful consideration as any other intervention or therapeutic interaction (Gabbard, 2001; Peterson \& Beck, 2003). It seems that even in face-to-face therapeutic practice, text-based communication is becoming increasingly inevitable (Gabbard et al., 2011; Leibert, Archer, Munson, \& York, 2006).

Despite the increased informal ICT use in face-to-face therapeutic practice, there is a lack of scholarly work on its benefits, issues and implications for practice (Gabbard et al., 2011; Mishna et al., 2014; Mishna et al., 2012; Mishna, Levine, Bogo, \& Van Wert, 2013). The majority of research examining ICT and therapy has examined formal online/e-therapy interventions. The most frequently studied therapeutic use of ICT involves clinical trials of CBT, and it is unclear the extent to which ICT has been incorporated into therapeutic settings across theoretical approaches (de Bitencourt Machado et al., 2016). The primary concern 
identified in the use of ICT in psychoanalysis is the loss of direct physical context or non-verbal feedback in the communication, potentially influencing the interpreted meaning of an exchange (de Bitencourt Machado et al., 2016). The informal incorporation of ICT communication into face-to-face therapy is unique. The dialogue can continue in the next session allowing multiple meanings to be clarified and the experiences of both the therapist and client can be analyzed with access to verbal and and non-verbal information when appropriate. Scholarly work on ICT and mental health has examined smart phone applications and texting as supplementary intervention tools for specific populations. Addressing the issue of the informal use of ICT, Mishna and colleagues (Mishna et al., 2012; Mishna et al., 2014) conducted a two-phase qualitative study on information and technology usage among clinical social workers, in order to examine how cyber communication has "crept" into traditional face-to-face practice. Analysis of focus groups with a total of 31 practitioners found that traditional face-to-face practice has been transformed by ICT, and that it is no longer possible not to engage in the use of ICT.

In phase one of the study, 16 practitioners took part in focus groups. Findings indicated that the participants considered ICT beneficial for administrative purposes such as scheduling appointments and conveying information about resources.

These same participants were invited to participate in focus groups in phase two and nine of the 16 were re-interviewed. Additional participants were recruited, with two criteria consisting of being less than 35 years (to ensure a younger cohort, which is considered relevant when examining ICT use) and having practiced in social work for fewer than five years. It became evident in phase two of the study that the practitioners who had participated in phase one had shifted in their views; in addition to finding ICT useful for administrative purposes they had come to find ICT also provided a new dimension in their practice, offering continuity of the 
therapeutic relationship through extending the session. According to respondents who had participated in phase one, "for this client knowing she can connect with me on email is very meaningful. Someone is hearing her. She has found someone she can trust"; and "Clients take strength in feeling they are connected to you" (Mishna et al., 2014, p. 182). This new dimension also was identified by respondents as helping clients process their thoughts and emotions and self-regulate. One practitioner stated for example, "some clients write their thoughts after the session. It helps them process and reflect on issues" (Mishna et al., 2014, 183). Another commented, "They're emailing me to say 'I need to share this with you'. It takes a bit of a burden off their shoulders. The stress and the anxiety of whatever they're suffering can be alleviated or decreased knowing that 'okay, I've shared, and I am able to now let this go until I see $\operatorname{xxx}^{\prime \prime}($ p. 183).

Participants also discussed challenges and contemplated how they could adapt ethical and clinical standards to the new reality of practice. In contrast to their previous reactivity to clients' contact through ICT, experienced practitioners described anticipating the dramatic change in expectations related to the availability due to the ubiquity of ICT. As an example a respondent described explaining "in a clear, kind, emotionally present way that I know there are times when the client may want to reach me, and while I would like to be available, I cannot be at all times" (Mishna et al., 2014, p. 183). Importantly the experienced practitioners recognized that it was necessary to address boundaries in an ongoing manner rather than only initially: "I revisit my boundaries as many times as I have to" (p. 183). The young and new practitioners, while clearly understanding the benefits of ICT, recognized the challenges, as evident by one respondent's comment that "it makes it a little bit stickier to keep the professional boundaries" (Mishna et al., 2014, p. 183). Some of these respondents explained that one way they manage boundaries is by 
having a separate phone and/or Facebook or Twitter account which they use only for work. Moreover, they explain to their teenage clients, "While I'm very friendly, my role is not to be your friend, but to help you find friends" (p. 183).

Although the Internet and social media have taken a central role in communication during the last decade, utilizing online text communication in the analytic process is still relatively novel. In this paper we posit that this mode of communication may enhance the patient's reflective capacities by providing a safe forum in which to express dissociated affects and self states, and to reflect on one's states of mind within a less intrusive relational context. We use a case illustration to demonstrate (SR). ${ }^{1}$

\section{Case Illustration (SR)}

Donna is a professional woman, who presented with extensive dissociative episodes related to experiences of rejection and abandonment. She attributed her poor ability to regulate her affect, anxiety regarding intimate others, and fear of abandonment, to her attachment history. Though initially very close to her mother, Donna reported that her life radically changed at nineteen months when her sister was born, and, according to her mother, Donna became an anxious, demanding and dysregulated child. Donna recalled an emotionally absent mother and a father consumed with his career. As a child, she remembered her parents as helpless and preoccupied, and as typically ignoring her and siding with her sister whenever the two argued or fought with each other. Donna recalled that she would become angry and even violent at this perceived injustice, and that her parents responded by helplessly accommodating, letting her have her way and buying her gifts. Sometimes however, they locked her in the dark basement

\footnotetext{
${ }^{1}$ All identifying information has been changed to ensure confidentiality
} 
until she calmed down. One vivid memory of Donna's was trying to reach out from underneath the basement door and crying, but no one came. This formative event became Donna's organizing principle, that others found her to be too much, and looked for ways to get rid of her. Sadly, she continued to enact this relational configuration with lovers, friends, therapists, and with me (SR) as she became increasingly more demanding and affectively dysregulated and they in turn felt overwhelmed, resentful and then withdrew, eventually terminating their relationship with her. Donna's hypervigilance to maternal affect and responsiveness interfered with the development of affect regulation skills and the ability to recognize her own internal states. Rather, she continually strove to please and achieve, which was the only way for her to gain her mother's validation, as a way of getting love and acceptance from others.

Donna learned that the way to gain attention and responsiveness was either through academic, athletic and professional achievements, or by engaging in extreme behaviors, such as threatening suicide and having regressive meltdowns. She described periods of intense despair and suicidality triggered by fear that she would be abandoned by intimate others. During these times Donna frequently dissociated, and resorted to self- injurious behaviors, such as cutting and scratching herself, and states of rage and aggression, which were later recounted to her by others as she did not remember these states. It is significant that in the midst of periods of suicidality and dissociation, Donna was able to hold a demanding professional job in the mental health field and to function well in her position (van der Hart, Nijenhuis, Steele \& Brown, 2004). Often, when she shared her insights regarding the children and parents with whom she worked, I (SR) felt deeply moved by her empathy and understanding for her severely abused, neglected and traumatized patients. Donna empathized with her patients' lives of despair and isolation through 
her own early and largely unformulated experience, which she often could not articulate, but was able to re-live and symbolize through her narratives about her patients.

Diverse self-states became activated during the treatment, including the abandoned and desperate child, the impulsive, suicidal and at times superficial adolescent, as well as an insightful and reflective adult self-state, which was mostly expressed through emails and through Donna's description and understanding of her patients. While the therapy began as twice weekly face-to-face treatment, I decided over time to develop a more flexible treatment frame that would offer greater holding and containment for Donna's unregulated affects and self states. This included face-to-face sessions, crisis telephone calls as needed, occasional sessions with Donna and her partner, and eventually cyber communication. This array of options made it possible for us to observe, and engage with a range of Donna's affects and self-states that may not have been available if there had been rigid adherence to a traditional treatment frame (Weisel-Barth, 2011). I believe that my availability and a flexible treatment frame was fundamental for Donna's treatment, though it also presented considerable challenges, as will be discussed below.

The fluid treatment strategy offered Donna greater safety, holding, and control, and a room for broader affective expression, and she demonstrated a growing capacity to become aware of her conflicting self-states. During the treatment process, I often experienced feelings of depletion and even apprehension of Donna's escalating logistical and affective demands. I also feared potential conflicts and disruptions that might emerge because of Donna's vulnerability to any perceived rejection and affective withdrawal and her intense fear and expectation that she would be abandoned. Another concern for me was that expanding the treatment frame beyond twice weekly sessions would eventually become unmanageable. 
I will discuss how the individual face-to-face sessions augmented with email communication appeared to facilitate the development of Donna's reflective functioning and capacity to become more aware of her affective shifts. In the concluding discussion, we will also discuss the challenges for the therapist in utilizing email as an adjunct to the face-to-face sessions.

\section{Clinical process}

During sessions, Donna often appeared to be in a regressive state, speaking in a childlike manner as she recounted her daily activities, or curled on the couch in a fetal position, feeling hopeless and despairing. She often gazed at me silently for long periods of time, watching my every move as if to make sure that I was present with her and fully attentive. She seemed to take me in like a very young child who relied on her sensory, tactile and visual system to establish contact, and to feel held and secure (Beebe \& Lachmann, 2015; 1994). This early developmental state was also apparent in Donna's focus on concrete details and events, and her inability to engage in more symbolic communication. She never remembered her dreams, and rarely shared her affective experience. We started to develop connections and internal structures through implicit, sensory and bodily communication, often in silence, rather than through words, symbolization or affective explorations (Grossmark, 2012). At times, Donna invited me to sit on the couch besides her as she showed her photos of friends and family. She did not describe the people or the nature of her relationship to them; rather, she just stated their names, as if inviting me to be a witness as we both quietly set next to one another. Donna desperately sought physical proximity and sensory connection, trying to avoid the possibility of being locked out and abandoned in the darkness. She repeatedly reminded me that as a child, she was rarely touched. She experienced this deprivation viscerally, and it was the most painful aspect of her lover's 
rejection. She told me how she sniffed her lover's pillow, and held it as she fell asleep alone, imagining that her lover was still with her.

At other times, Donna became enraged or suicidal, blaming me for not doing enough and demanding that I actively intervene in her conflicts with her partner, answer her despairing phone calls immediately, and allow her to remain in the office as long as she needed. Donna lacked self soothing and affect regulation skills, which develop in the context of parent/child affective interactions, and constantly sought others to help regulate her through physical holding and sensory connection (Beebe \& Lachmann, 2015). When this holding was withheld, Donna engaged in self-harming behaviors such as cutting, to help regulate her extreme affective shifts. At other times, however, Donna showed considerable reflective skills as she described her own patients, and shared her deep understanding for their traumatic experiences. For example, Donna told me about a boy to whom she became extremely attached, who was severely abused and neglected, and whose adoptive mother rarely touched or held him. Donna described how the boy often became violent and destructive, incurring further punishment and rejection by his mother. Donna understood the boy's desperate loneliness and frustration. She held him, as she herself wished to be held, verbalized to him his anger and despair, and taught his mother to be more loving so as to repair the severe neglect and abuse he has experienced. Through her relationship with the boy and his adoptive mother, Donna tried to repair her own lonely childhood and lack of physical and emotional touch, as well as her violent attempts to gain love and attention.

I found myself in shifting affective states in response to Donna. During their periods of silent, implicit communication, when I experienced Donna as a young child who was frightened, desperate and in need of reassurance and holding (Beebe, Lachmann, Markese \& Bahrick, 2012), I felt close to and protective of Donna. I was deeply touched by Donna's thoughtful and 
empathic feelings towards her patients. However, I also found myself accommodating Donna's demands for her time and flexibility to a point well beyond my personal and professional limits. Consequently, I often felt overwhelmed and resentful, and eventually started to withdraw. This entailed no longer answering Donna's phone calls between sessions, and feeling distant and disconnected from her during sessions. Not quite aware of the enactment taking place between us, I did not disclose to Donna my conflicting feelings. Donna, noticing my affective withdrawal, responded to this sequence by crying and apologizing, terrified that I would "fire" her as had several of her previous therapists.

We enacted an old familiar dance, similar to the pattern in which Donna engaged with her mother and her partner. Like me, Donna's partner initially accommodated her, only to eventually feel resentful and withdraw in response to Donna's intense and never-ending needs and demands. As I became more aware of what was enacted between us, I decided to abandon the "illusion of analytic attunement" and perfect emotional holding (Slochower, 1996, p. 323), and rather, to share with Donna my subjective experience. While I felt it was important to hold and connect with Donna's primitive self-states, I recognized that we both needed to maintain limits and boundaries in order to preserve the treatment, and in order to preserve my own capacity to survive the treatment (Winnicott, 1963). This shift from the 'habitual' therapeutic mode could be considered a 'now moment' as it was a spontaneous response which allowed an opening or an expansion of the therapeutic field between Donna and myself (Stern, Sander, Nachum, Harrison, Lyons-Ruth, Morgan, et al., 1998). During the intense interaction that took place between us I shared my frustration and sense of depletion as a response to Donna's demands and expectations. Donna expressed her disappointment in me, and her fear of being rejected and abandoned. This emotional exchange between us led to greater openness as Donna 
became more attuned to her own affective states, and more concerned about preserving me (Beebe \& Lachmann, 2015).

In a recent paper, Aron and Atlas (2015) assert that enactments are not only a replay of past relational patterns and encounters, but are also an improvisational mode for future engagements (Ringstrom, 2007). In that sense, enactments encapsulate both the old and the new, and contain possibilities for the leading edge of relational change (Tolpin, 2007). Our spontaneous exchange of the subjective experience between us allowed us to shift from ongoing enactment of old patterns of demand and withdrawal, to new relational possibilities of mutuality and affective sharing. This interaction contributed to Donna's capacity to symbolize, reflect and become more aware of the other's affective experience. She became more curious about her experience of herself alone and in relation to another and she gradually, and spontaneously, proceeded to share her insights with me via emails (Fonagy \& Bateman, 2008; Fonagy, Gergely, Jurist, \& Target, 2002). Rather than remaining trapped in a pattern of mutual accommodation, it became possible for us to express aversive affects and sustain emotional collisions. It ultimately led to a more authentic and reciprocal relationship.

Donna started to send me emails on her own volition, and her e-mail communications became an integral, though unplanned aspect of the treatment. As I read her emails, I recognized that this form of indirect communication allowed Donna to access greater capacity to reflect and symbolize her experience and to contain her affect, and therefore encouraged Donna to continue. While I did not actively respond to these emails except to acknowledge them (emailing Donna that I had received her message and would discuss it with her in the following session), I tried to engage Donna during subsequent sessions, not always successfully, in elaborating and expanding on their meaning. In her emails, Donna reflected on her affective states, dissociative triggers, 
and relational difficulties, and she became more aware of her affective shifts and inner experience in response to relational interactions.

The disembodied cyber communication allowed both Donna and I to move from a stance of crisis management and intense affective engagement to mutual reflection and curiosity regarding Donna's dissociative episodes and her need for touch and holding, and over time, offered Donna the possibility of greater awareness and integration.

\section{Donna's emails}

While we discussed her emails in subsequent sessions, I did not engage Donna with an inquiry about her experience of composing and sending her emails. I believed that such inquiry would be experienced by her as intrusion on her private reflective space, and on her emerging capacity to be curious about her own inner world. I recognized that an unobtrusive stance was required to help Donna shift from a more primitive, fragmented self experience to greater integration and affective stability (Grossmark, 2012). I encouraged Donna, however, to reflect and elaborate on the meaning of her emails, and Donna gradually became more willing to discuss the content of her communications in relation to her subjective and relational experience. The following email arrived after our discussion of Winnicott's transitional object in relation to Donna's need for holding and affection:

One of the things going on with me is that idea that I am empty and I find myself in another, so when I lose a romantic partner I am actually losing a piece of myself. In some ways I can see it being beneficial to have something to hold and hug when she is not there that she gave to me or I identify with her. On the other hand, I can see this being detrimental as one of my goals is to be able to gain an independent sense of self that is not tied to another human being. 
While reading this email, I was struck by Donna's ability to articulate and reflect on her subjective experience and affective needs. Her email indicated that Donna seemed aware of her primitive need for merger and longing for dependence and had started to recognize that this interfered with her simultaneous quest for adult autonomy and agency. When I shared my observations with her in the following session, Donna dismissively responded that she had copied her words directly from Wikipedia. She seemed to disavow her online reflections as if this was an alien self-state, or perhaps to discourage me from being too hopeful for her potential recovery and eventual termination, thereby threatening the growing but fragile therapeutic bond.

Possibly, the fabrication from Wikipedia was akin to the development of a "false self" in an attempt to find an alternative way to be recognized and appreciated by the therapist (Gabbard, 2001). Indeed, during this period of the treatment, I often felt overwhelmed and depleted by Donna's affective instability, self-harm and suicidal threats, as well as her demand that I be available either personally or by phone whenever a crisis occurred. Although not aware of my motives at the time, my encouragement of cyber communication may have also been an inadvertent attempt at self-preservation.

As Donna continued to engage in online communications, however, her emails began to suggest greater authenticity, and seemed to enable Donna to maintain a reflective space. Such space was often not possible during sessions, when intersubjective affects, her longing to be held and feel connected, and her fear of rejection and abandonment interfered with Donna's capacity to utilize her reflective functions. In her next email, Donna started to recognize the process of fragmentation that often accompanied and followed painful and frightening relational experiences, and observed her emerging capacity to be more present during dissociative episodes: 
I guess I am just interested in exactly what I am going through...being so high functioning and effective one minute but then having a GAF drop about 60 points to the point of being completely nonfunctional at perceived rejection or abandonment by a significant other. I guess the only way I can describe this change is a form of dissociation and it was complete in the past, like another person takes over. Now, though, when I get into the state, I know cognitively what's going on, that these are bad choices, but I feel fully and totally unable to stop them. I don't think I ever labeled this as dissociation until this year. .... So I'm confused, but I guess that is what makes me unique is that things are happening concurrently... literally, I can step into the car after a session (during work) as an adult, get my partner on the phone and fall back into that state in a matter of seconds... please let me know your thoughts.

Donna was clearly quite excited about her new insight, which she wanted to share with me. In the following session, we reflected together on her dissociative triggers, and we discussed how dissociative processes manifested during the session when Donna perceived my affective withdrawal and became flooded by fear of loss and abandonment.

Incrementally, Donna started to be aware of, and remember regressive self-states although she continued to feel she had no control over these. Previously she had no memory of such episodes, and would later experience deep shame when they emerged and were commented upon by others. She was beginning to maintain her reflective function even during times of extreme fear and distress. Donna then sent me a note she had emailed to her partner so we could discuss it in the following session. In this email, she seemed to connect with her own experiences of loss and rejection so as to facilitate a process of empathic resonance with her partner's state of mind (Fonagy et al, 2002): 
We did a powerful exercise in group last week where they asked us to see the world through someone else's eyes and I thought of you (her partner). And what you were brought me to tears in a way I have never experienced before with any other person. I saw the world through the eyes of a small girl who was hurt by feeling unwanted and being hurt over and over again by someone she trusted. And then trying to express her pain and having no one listen or help her.

Donna wanted me to see that she had started to develop a capacity to know and understand her partner's experience and emotional pain and rejection. This was a significant shift for Donna, who, although empathic in her professional life, was typically preoccupied by her own needs and thus unable to be aware of those of others. Donna was able to empathize with her partner's experience in the relationship and to recognize her partner's own childhood trauma and emotional fragility.

In these emails, Donna appeared to ponder her responses to relational disruptions, her dissociative shifts, and another person's state of mind related to grief and attachment trauma. This gave me and Donna the opportunity to create an affective and temporal protected space from impending crisis, emotional flooding, and dissociation, and to utilize ongoing awareness as well as reflective functioning (Straker, 2011). Donna's desire to please and her vigilance of my expressions and responses did not interfere or hover over our communication process. As a child who had to be ever watchful for her mother's inconsistent attentiveness, worried that she may be forgotten and abandoned at any moment, Donna became anxious and apprehensive during faceto-face encounters with me, wondering for instance, why my gaze seemed distracted, whether I was looking at the clock, and why I seemed to move my chair further away. She found it difficult to tolerate any signal of withdrawal or rejection, and was hyper attuned to any shift in 
the implicit relational processes between us. During our online exchanges, the threat of my subjectivity receded (Grossmark, 2012), although I remained present as a disembodied witness, providing Donna with affective holding and validation (Mishna et al., 2015). Online communication thus became a potential space that allowed Donna to develop insight and to reflect on her experience while freeing her from anxiety and vigilance in the presence of the other.

When I asked Donna for her permission to write this paper, she became very enthusiastic, at some point even proposing to travel to the conference where this paper was to be presented (that did not happened for a number of reasons). I shared with Donna an initial version of the clinical portions of this paper, and she offered some revisions of her own, pleased that some of her own words were included verbatim. In a sense, it was a mutual endeavor to which both of us contributed.

\section{Discussion}

Although the use of information and communication technology as an informal adjunct to face-to-face therapy is in its early stages, some literature identifies potential benefits, such as continuity in the therapeutic relationship (Mishna et al., 2015). An additional benefit is the greater ease offered for patients who may have difficulty expressing themselves in person. For example, patients who are guarded during face-to-face sessions may send emails after a session or before the following session in which they express themselves more fully (Mishna et al., 2012). Cyber technology can thus assist communication in the therapeutic setting and be used as an informal adjunctive method through which patients can engage more fully with the therapist (Bradley \& Hendricks, 2009; Rochlen, Zack \& Speyer, 2004). 
Cyber communication may provide some patients with temporal and proximal space to reflect upon their state of mind (Wright, 2002). As was the case with Donna, it can allow the freedom to express oneself with a level of openness that is difficult for some to tolerate in the physical presence of the therapist (Gabbard, 2001). Writing emails has been compared to keeping a journal or a diary. Although journaling and letter writing is generally accepted into the realm of psychotherapy, there remains little known about the mechanisms through which these means achieve positive results (Gelso, Kerner, \& Fitzpatrick, 2007). Text-based cyber communication can help support and empower the patient, and be a way to "enhance selfreflection and ownership of the therapeutic process" (Rochlen, et al., 2004, p. 271). Moreover, therapists have drawn parallels between cyber counseling and journaling, noting similarity in the catharsis that occurs due to writing one's feelings but different as cyber communication is “a conversation between two people so it was more interactive than journaling... instead of just writing into a journal where no one would see it, it's like now someone is reading this and responding in a way that's really good" (Mishna et al., 2015, p. 174). Finally, cyber communication may help patients who experience dissociation as a result of attachment trauma to reflect on fragmented self-states and "stand in the spaces" (Bromberg, 1998), a process that can be experienced as dangerous and inaccessible during face-to-face therapeutic interactions.

Text-based technology such as texting and e-mail are distinct from the use of telepsychology or video-therapy in that they allow private reflection similar to journaling, yet with a stronger connection to the therapeutic relationship. In this they are perhaps comparable to the use of the telephone in therapy. The use of the telephone has long been accepted for administrative aspects of psychoanalysis such as scheduling appointments (Bhuvaneswar \& Gutheil, 2008). Similar to ICT, discussions regarding telephone use in analysis have identified 
the loss of non-verbal communication when tele-analysis is a consistent substitute for face-toface therapy (Scharff, 2012). Yet the use of the telephone has been argued to be at least comparable if not superior to face-to-face treatment, with the potential to enhance and intensify such processes as client self-discovery and empathic listening by the therapist (Aronson, 2000). The clear and thoughtful use of the telephone as an addition to the therapeutic process in dialectical behaviour therapy (DBT) hints at the potential for text-based technology use alongside face-to-face therapy (Bhuvaneswar \& Gutheil, 2008). Despite the similarities, there are important differences. The use of the telephone in DBT has very clear parameters, and allows therapists to regulate time frames and therefore establish boundaries on its use (Bhuvaneswar \& Gutheil, 2008). As discussed in the case illustration, for patients like Donna, with whom the therapist is looking to increase security and decrease anxiety, text-based technology may allow greater flexibility for personal reflection. While expectations can still be established regarding the responses by the therapist, as was the case with Donna, e-mails can be written whenever and wherever the patient feels safe; there are social conventions however, regarding when one can telephone someone (Gabbard, 2001). The perception of connection while simultaneously having unstructured time and privacy to write and reflect in text-based cyber communication may create the opportunity for potential space, unencumbered by the destabilizing aspects of face-to-face or even telephone interactions, which can be difficult for patients with attachment insecurity (Whitty \& Carr, 2006; Winnicott, 2005). This is similar to the use of the telephone as a transition space described by Aronson, whose "patient could not tolerate the usual comings and goings of the treatment situation, which impose an experience of separateness" (Aronson, 2000, p. 147). When reflecting on Donna's treatment, it seems clear that email communication provided her with a potential space that allowed greater reflexivity 
protected from the therapist's (SR) presence and potential intrusion. At the same time, it may have been a challenge for Donna due to her intense need for immediate responsiveness and her deep fear of abandonment. Having to wait for the therapist's response within the structure of twice weekly sessions, however, seemed to help regulate Donna's anxiety and help develop her capacity to be alone (in the virtual presence of the other).

Text-based ICT may create greater safety, as the sensory and affective signals a patient like Donna craves may also increase the patient's anxiety regarding intimacy with the therapist. The use of e-mail can create "a self preservation barrier to intimacy" (Gabbard, 2001, p. 726). Donna's e-mail, cut and pasted from Wikipedia, may have been a tentative test of the process, a way to gauge the therapist's reaction without yet risking vulnerability of putting herself directly within the dialogue. The ultimate goal is to bring more of the patient's authentic self into the therapy, and for Donna this began by using e-mail to create a safe space, which then allowed a more spontaneous self- expression, promoted deeper reflection and led to her recognition of dissociative triggers that could then be addressed in face-to-face therapy.

For some patients, online communication may also have the potential to dilute the intersubjective aspects of the therapeutic process, however, thereby creating a disembodied dimension that lacks the immediacy and intensity of face-to-face engagement. As noted, the option for online communication may inadvertently create enactments that may be difficult to identify and process, because of the lack of sensory and affective signals during patient/therapist interactions. With patients like Donna, who desperately need the visceral, sensory level of bodily and affective connection to feel loved and held, online engagement may be experienced as too removed and abstract. Such considerations are in-line with those identified by Barth when striving for balance between separation and connection in the use of the telephone in 
psychoanalysis (Aronson, 2000). Additionally, for those patients who exhibit borderline pathology, the potential for unfettered access to the therapist may serve to erode the time tested therapeutic boundaries that are reinforced through scheduled sessions (Bhuvaneswar \& Gutheil, 2008). Actual or perceived access to the therapist outside of structured and scheduled appointment times may prove too difficult to manage. As it is very early on in the use of textbased cyber technology in therapeutic settings it is premature to identify or generalize to specific populations with whom it may be most effective.

Informal text-based technology as an adjunct to face-to-face therapy should be introduced in a thoughtful way, considering the implications for the client in relation to the therapeutic relationship (Peterson \& Beck, 2003). Expectations regarding therapist response to communication should be made explicit and these should consider the implications for transference and countertransference when clients become privy to daily routines of therapists outside of session times through the additional information that often comes with technology based communication, such as the time an e-mail is sent (Bhuvaneswar \& Gutheil, 2008). Additionally, it is argued that all forms of extra communication be brought into the context of face-to-face therapy and become part of the psychoanalytic process (Gabbard, 2001).

Of course, the discussion should include the therapist's own self-interest and self-care as well as their motivations in making use of informal cyber communication. In working with patients like Donna, the therapist must be mindful of his or her emotional survival, personal limits, and need for self-preservation, as well as the requirement for a reflective space of their own from which to formulate and conduct the treatment (Slochower, 1996). 
In the scant literature on the informal use of information and communication technology, there is a focus is on the risks and need for guidelines and standards of practice. Literature is required to examine how information and communication technology can informally supplement face-to-face practice in a beneficial and ethical manner that furthers the therapeutic process and contributes knowledge for analytic practice. To achieve this goal, it will be essential to obtain not only clinicians' perspectives, but patients' perspectives as well (Mishna et al., 2015). A study conducted by Mishna and colleagues (2015) found that for the clients, who were undergraduate students, cyber was an extension of the relationship, as they felt the therapist was there for them somewhere in the cyber world 'most anytime.' Because they envisioned their therapist as continually available through the cyber medium, their sense of connection with the therapist was extended. The undergraduate student clients' experience of a 'holding environment' (Winnicott, 1965) was strengthened by re-reading what their therapists wrote to them, whenever they wished" (Mishna et al., 2015, p. 178).

While the focus of this paper is text based online communication, the challenges and opportunities of online communication in treatment, and its potential to provide a reflective space for certain patients, it is important to note that other adjunctive treatment modes include letter writing, phone communication, texting and messaging, as well as video based treatment such as Skype and Face Time. These options have become quite pervasive and have created both old and new possibilities to augment in-person treatment. The growing literature on information and communication technology in therapy requires further theoretical, practical and technical elaboration to identify the benefits and address a range of complex issues (See Aronson, 2000, Essig, 2012; Scharff, 2012), as well as more extensive research. 


\section{References}

Abbott, J.M., Klein, B., \& Ciechomski, L. (2008). Best practices in online therapy. Journal of Technology in Human Services, 26(2/4), 360-375. doi: 10.1080/15228830802097257

Aron, L. \& Atlas, G. (2015). Generative enactment: Memories from the future. Psychoanalytic Dialogues, 25, 309-324.

Aronson, J. K. (Ed.). (2000). Use of the Telephone in Psychotherapy. Northvale, NJ: J. Aronson.

Barak, A., Hen, L., Boniel-Nissim, M., \& Shapira, N. (2008). A comprehensive review and a meta-analysis of the effectiveness of internet-based psychotherapeutic interventions. Journal of Technology in Human Services, 26(2-4), 109-160.

Beebe, B. \& Lachmann, F. (1994). Representation and internalization in infancy: Three principles of salience. Psychoanalytic Psychology, 11, 127-165.

Beebe, B., Lachmann, F., Markese, S., \& Bahrick, L. (2012). On the origins of disorganizied attachment and internal working modesl, \#1. A dyadic systems approach. Psychoanalytic Dialogues, 22, 352-374.

Blais, J., Craig, W.M., Pepler, D.J., \& Connolly, J. (2008). Adolescents online: The importance of Internet activity choices to salient relationships. Journal of Youth and Adolescence, 37(5), 49-58. doi: 10.1007/s10964-007-9262-7.

Bhuvaneswar, C. G., MD \& Gutheil, T. G., MD. (2008). E-mail and psychiatry: Some psychotherapeutic and psychoanalytic perspectives. American Journal of Psychotherapy, 62(3), 241-61.

Bradley, L.J., \& Hendricks, B. (2009). E-mail and ethical issues. The Family Journal: Counseling and Therapy for Couples and Families, 17(3), 267-271. doi: $10.1177 / 1066480709338293$ 
Bradley, L., Hendricks, B., Lock, R., Whiting, P., \& Parr, G. (2011). E-mail communication:

Issues for mental health counselors. Journal of Mental Health Counseling, 33(1), 67-79.

Bromberg, P. (2011). Awakening the dreamer. NY: Routledge.

Bromberg, (1998). Standing in the spaces: Essays on clinical process, trauma and dissociation. Hillsdale, NJ: Analytic Press.

de Bitencourt Machado, D., Braga Laskoski, P., Trelles Severo, C., Margareth Bassols, A., Sfoggia, A., Kowacs, C., . . Laks Eizirik, C. (2016). A psychodynamic perspective on a systematic review of online psychotherapy for adults. British Journal of Psychotherapy, 32(1), 79-108. doi:10.1111/bjp.12204

Dowling M., \& Rickwood D. (2013). Online counseling and therapy for mental health problems: A systematic review of individual synchronous interventions using chat. Journal of Technology in Human Services, 31, 1-21.

Dunn, K. (2012) A qualitative investigation into the online counselling relationship: To meet or not to meet, that is the question. Counselling and Psychotherapy Research, 12(4), 316326.

Essig, T. (2012). Psychoanalysis lost and found in our culture of simulation and enhancement. Psychoanalytic Inquiry, 32, 438-453.

Fonagy, P., \& Bateman, A. (2008). The development of borderline personality disorder-A mentalizing model. Journal of Personality Disorders, 22(1), 4-21.

Fonagy, P., Gergely, G., Jurist, E, \& Target, M. (2002). Affect regulation, mentalization and the development of the self. NY: Other Press.

Gabbard, G.O. (2001). Cyberpassion: E-Rotic Transference on the internet. The Psychoanalytic Quarterly, 70, 719-737. 
Gabbard, G.O., Kassaw, K.A., \& Perez-Garcia, G. (2011). Professional boundaries in the era of the internet. Academic Psychiatry, 35(3), 168-174.

Gelso, C. J., Kerner, E. A., \& Fitzpatrick, M. R. (2007). Integrating writing into psychotherapy practice: A matrix of change processes and structural dimensions. Psychotherapy: Theory, Research, Practice, Training, 44(3), 333-346. doi:10.1037/0033-3204.44.3.333

Grossmark. R. (2012). The unobtrusive relational analyst. Psychoanalytic Dialogues, 22(6), 629646.

Hanley T. (2009). The working alliance in online therapy with young people: preliminary findings. British Journal of Guidance \& Counselling, 37(3), 257-269.

Janet, P. (1925). Psychological healing, 1-2. NY: McMillan. (Original publication, 1919).

Leibert, T., Archer Jr., J., Munson, J., \& York, G. (2006). An exploratory study of client perceptions of Internet counseling and the therapeutic alliance. Journal of Mental Health Counseling, 28(1), 69-83.

Lyons-Ruth, K., Dutra, L., Schuder M., \& Bianchi I. (2006). From infant attachment disorganization to adult dissociation: Relational adaptations or traumatic experiences? Psychiatric Clinics of North America, 29, 63-86.

Peterson, M. R., \& Beck, R. L. (2003). E-mail as an adjunctive tool in psychotherapy: Response and responsibility. American Journal of Psychotherapy, 57(2), 167-81.

Migone, P. (2013). Psychoanalysis on the Internet: a discussion of its theoretical implications for both online and offline therapeutic technique. Psychoanalytic Psychology, 30(2), 281299. doi: $10.1037 / \mathrm{a} 0031507$.

Mishna, F., Bogo, M., Root, J., \& Fantus, S. (2014). Here to stay: Cyber communication as a complement in social work practice. Families in Society, 95(3), 179-186. doi: 
10.1606/1044-3894.2014.95.2.

Mishna, F., Bogo, M., Root, J., Sawyer, J., \& Khoury-kassabri, M. (2012). "It just crept in”: The digital age and implications for social work practice. Clinical Social Work Journal, 40(3), 277-286. DOI: 10.1007/s10615-012-0383-4.

Mishna, F., Bogo, M., \& Sawyer, J. (2015). Cyber counseling: Illuminating benefits and challenges. Clinical Social Work Journal, 43(2), 169-178.

Mishna, F., Levine, D., Bogo, M., \& Van Wert (2013). Cyber counselling: An innovative field education pilot project. Social Work Education, 32(4), 484-492.

DOI.org/10.1080/02615479.2012.685066.

Mishna, F., Fantus, S. \& McInroy, L. B. (2016). Informal use of information and communication technology: Adjunct to traditional face-to-face social work practice. Clinical Social Work Journal, 1-7. doi: 10.1007/s10615-016-0576-3.

Murphy, L., Parnass, P., Mitchell, D., Hallett, R., Cayley, P., \& Seagram, S. (2009). Client satisfaction and outcome comparisons of online and face-to-face counselling methods. British Journal of Social Work, 39(4), 627-640. doi: 10.1093/bjsw/bcp041.

Perron, B., Taylor, H., Glass, J., \& Margerum-Leys, J. (2010). Information and communication technologies in social work. Advances in Social Work, 11(1), 67-81. Retrieved from http://deepblue.lib.umich.edu/bitstream/handle/2027.42/78034/46.pdf;jsessionid=99D502 2CBF1037EB371F871589B199F1?sequence=1

Preschl, B., Maercker, A., \& Wagner, B. (2011). The working alliance in a randomized controlled trial comparing online with face-to-face cognitive-behavioral therapy for depression. BMC Psychiatry, 1: 189. DOI: 10.1186/1471-244X-11-189.

Richards D., \& Vigano N. (2013). Online counseling: a narrative and critical review of the 
literature. Journal of Clinical Psychology, 69(9), 994-1011.

Ringstrom, P. (2007). Scenes that write themselves: Improvisational moments in relational psychoanalysis. Psychoanalytic Dialogues, 17, 69-99.

Rochlen, A.B., Zack, J.S., \& Speyer, C. (2004). Online Therapy: Review of relevant definitions, debates, and current empirical support. Journal of Clinical Psychology, 60(3), 269-283. doi: $10.1002 /$ jclp. 10263

Scharff, J. S. (2012). Clinical issues in analyses over the telephone and the internet. The International Journal of Psychoanalysis, 93(1), 81-95. doi:10.1111/j.17458315.2011.00548.x

Slade, A. (2014). Imagining fear: Attachment, threat and psychic experience. Psychoanalytic Dialogues, 24(3), 253-266.

Slochower, J. (1996). Holding and the fate of the analyst's subjectivity. Psychoanalytic Dialogues, 6, 323-53.

Stern, D.N., Sander, L.W., Nachum, J.P., Harrison, A.M., Lyons-Ruth, K., Morgan, A.C., Bruschweilerstern, N., \& Tronick, E.Z. (1998). Non-interpretive mechanisms in psychoanalytic therapy: The 'something more' than interpretation. The International Journal of Psychoanalysis, 79, 903-921.

Straker, G. (2011). Shaping subjectivities: Public memories, public archives. Psychoanalytic Dialogues, 21, 643-657.

Tolpin, M. (2007). The divided self: Shifting an intrapsychic balance, the forward edge of a kinship transference, to bleed like everyone else. Psychoanalytic Inquiry, 27, 50-65. van der Hart, O., Nijenhuis, E. Steele, K, \& Brown D. (2004). Trauma related dissociation: Conceptual clarity lost and found. Australian and New Zealand Journal of Psychiatry, 
38, 906-914.

van der Kolk, B. A. (2002). Posttraumatic therapy in the age of neuroscience. Psychoanalytic Dialogues, 12, 381-392.

van der Vaart, R., Witting, M., Riper, H., Kooistra, L., Bohlmeijer, E.T., \& JEWC van Gemert -Pijnen, L. (2014). Blending online therapy into regular face-to-face therapy for depression: Content, ratio and preconditions according to patients and therapists using a Delphi study. BMC Psychiatry 2014, 14, 355.

Whitty, M. T., \& Carr, A. N. (2006). New rules in the workplace: Applying object-relations theory to explain problem internet and email behaviour in the workplace. Computers in Human Behavior, 22(2), 235-250. doi:10.1016/j.chb.2004.06.005

Weisel-Barth, J. (2011). Katherine: A long hard case. International Journal of Psychoanalytic Self Psychology, 6(4), 444-468.

Winnicott, D.W. (1963). The development of the capacity for concern. The maturational processes and the facilitating environment (pp. 73-82). Madison, CT: International Universities Press.

Winnicott, D. W. (1965). Playing and reality. London: Tavistock. (Original publication, 1971). 